\title{
Investigating Interdiscursivity in Hospital Strategic Plans Using Fou- cauldian Discourse Analysis
}

\begin{abstract}
Critical genre analysis (CGA) investigates the impact of context on genres by analyzing interdiscursivity (the integration of discourses in genres), but there has been a shortage of discussion of specific methods. This paper demonstrates that Foucauldian discourse analysis (FDA) - specifically, statement function analysis - constitutes a very useful approach with which to analyze interdiscursivity in CGA. Analysis of the move of "priorities/goals" (Cornut et al. 2012) in three strategic plans produced by British hospitals using FDA reveals three main discourses: strategic management, public service accountability, and patient centeredness. As interdiscursive analysis reveals the discursive foundations of organizational practices, CGA is well-positioned to make many valuable contributions to organizational research.
\end{abstract}

\section{Keywords}

Critical genre analysis, interdiscursivity, Foucauldian discourse analysis, hospital strategic plans, organizational research

\section{Introduction}

Critical genre analysis (CGA) reflects the growing trend within genre studies of recognizing the influence of context on genre (Bhatia 2010, Frow 2015). A central concept in CGA is interdiscursivity. It has been defined as the integration of discourses, understood as "larger systems of knowledge, values and social relationships that grow up within societies and cultures" (Jones 2012: 15), for strategic purposes in genres (Bhatia 2010, Candlin 2006, Koskela 2013). In CGA, these discourses are scrutinized for what they reveal about professional practices and cultures.

One aspect within CGA that warrants greater attention is method, particularly methods used to analyze interdiscursivity. Empirical studies of interdiscursivity in the CGA tradition tend to reflect a pragmatic approach, where methods are drawn from various approaches to text and discourse analysis. This open-endedness may reflect the fact that CGA is young and still evolving as an approach to genre (Bhatia 2012). The present paper is undertaken in the hope of stimulating further discussion about approaches that can support the analysis of interdiscursivity within the framework of CGA. Specifically, it aims to show that Foucauldian discourse analysis (FDA) constitutes a very useful analytical approach for interdiscursive analysis. It demonstrates FDA's compatibility with the overarching aims of interdiscursive analysis in CGA, noting many correspondences between Foucault's (1972) seminal theory of discourse and subsequent definitions of interdiscursivity (Bhatia 2010, Candlin 2006, Chouliaraki/Fairclough 1999). It presents statement function analysis, illustrating how it can be used to analyze a data set of strategic plans available online. Analyzing interdiscursivity in organizational genres makes it possible to identify salient aspects of the broader context within which organizations operate. As such, besides making specific contributions to CGA, the present paper contributes analytical approaches to the field of organizational studies.

\footnotetext{
* Antoinette Fage-Butler

Department of Business Communication

Aarhus BSS, Aarhus University

Jens Chr. Skous Vej 4

8000 Aarhus $C$

Denmark

butler@bcom.au.dk
} 
The article proceeds as follows. First, interdiscursivity as a key concern of CGA is discussed in relation to intertextuality, Foucauldian discourse theory, trends within the field of genre studies, and existing analytical approaches in CGA. Then, statement function analysis is presented and used to analyze interdiscursivity in the strategic plans of three British hospitals that have been published online. The paper concludes with a discussion of implications and suggestions for future research.

\section{Interdiscursivity}

\subsection{Interdiscursivity vs. intertextuality}

Context affects the language of genres both intertextually and interdiscursively. Intertextuality (e.g. Bakhtin 1986, Frow 2015, Kristeva 1980) relates to specific texts' relationship to other specific texts. It involves borrowings between texts, also called "manifest borrowing" (Fairclough 1992: 271), evident, for example, in direct citations or parodic references between texts (Allen 2000, Genette 1997). Interdiscursivity, which is the focus of this paper and is the less investigated of the two, particularly from a genre perspective (Bhatia 2010: 33), has to do with the relationship of texts to broader discursive resources. Interdiscursive analysis provides a means of examining how the sender (text-producer) employs the discourses circulating in society strategically. Kain (2005: 381) emphasizes the potential inventiveness associated with the incorporation of discourses associated with various discourse communities. The issue of discursive choice is of primary interest in CGA, with interdiscursive analysis providing insights into senders' aims and the broader context, such as an organization's culture. The introduction of discourses with attendant values and constructs into genres also helps professional communities in "constituting themselves, their members, and their relationships to other communities" (Kain 2005: 377).

\subsection{Parallels between interdiscursivity in CGA and Foucauldian discourse theory}

\subsubsection{Discourse and interdiscursivity}

Although the term 'interdiscursivity' is not employed in Foucault (1972), the foundations for theories of interdiscursivity are evident in this text, no doubt because interdiscursivity relies on a notion of discourse, and Foucault (1972) has become "the locus classicus for the definition of discourse" (Soyland/Kendall 1997: 11).

Foucault (1972) emphasizes the 'commonplaceness' of discourses by describing them as being constituted by statements that have been uttered or written in actual communicative situations. When statements cluster around a particular topic and bear points of 'common-ness' in relation to that topic, there is a discourse, or discursive formation (Foucault 1972: 38). Discourses are time- and place-sensitive, and there are often multiple discourses about a single topic circulating at any one time. Foucault also calls discourses "orders of discourse" (Foucault 1972: 31; 1971), and emphasizes the exclusionary qualities of discourse, where some things can be said whilst others cannot.

According to Foucault (1972), choice of discourse is affected by three factors:

- it is motivated by strategic concerns regarding "the function that the discourse under study must carry out in a field of non-discursive practices" (Foucault 1972: 68)

- it is the result of individual choices made by those who are considered legitimated to "speak" and "access" a discourse (Foucault 1972: 68), whom Foucault identifies as having professional status

- it is affected by considerations of the aspirational or symbolic power of a discourse, particularly in relation to how particular discourses are considered to generate "phantasmatic representation[s]" (Foucault 1972: 68), or desirable values or outcomes (see also Glynos/ 
Howarth 2007: 17)

In other words, strategy, professional choice and likely desirable effects influence choice of discourse(s).

Subsequent theories of interdiscursivity draw on elements of Foucauldian discourse theory. Although Fairclough (1992: 271) defines interdiscursivity to mean the incorporation of genres and styles as well as discourses into genres, his theory of interdiscursivity refers explicitly to Foucault's theory of "order of discourse" (Fairclough 1992: 284). For Chouliaraki/Fairclough (1999), interdiscursive analysis provides an optic on society, and Candlin/Maley (1997: 212) similarly interpret interdiscursivity as shedding light on both discourse and social practices, concerns which are directly traceable to Foucault, who describes discourse as practice (Foucault 1972, Hook 2001). Frow (2015: 19) also underlines the similarity between genre(-as-practice) and discourse(as-practice) as follows: "Discourses - by which Foucault here means something very close to what I call genres - are performative structures that shape the world in the very process of putting it into speech".

Bhatia (2010: 35) defines interdiscursivity as follows:

\begin{abstract}
Interdiscursivity [...] refers to more innovative attempts to create various forms of hybrid and relatively novel constructs by appropriating or exploiting established conventions or resources associated with other genres and practices [...]. [I]nterdiscursivity can be viewed as appropriation of semiotic resources (which may include textual, semantic, socio-pragmatic, generic, and professional) across any two or more of these different levels, especially those of genre, professional practice and professional culture.
\end{abstract}

Here, Bhatia emphasises how discursive elements generate fluidity in genres and support the sender's strategic aims, again reminiscent of similar statements by Foucault (1972), noted earlier in this section. It is, moreover, significant that Bhatia (2010: 39) sees discursive appropriations as operating in "socio-pragmatic space". Essentially, socio-pragmatics relates to a priori understandings which affect how objects can be imagined, limiting the abundance of meanings that objects otherwise might have, and the actions that are seen to be legitimate in relation to those meanings (Foucault 1972, Mey 2001, Simons 1995). As a priori understandings both condition and reflect professional practice and professional culture, interdiscursive analysis in CGA sheds valuable light on the cultural frames within which organizations communicate. Although Bhatia mentions a number of semiotic resources, it should be noted that this paper focuses on discourses only. This delimitation is deliberate, as the aim is to showcase the exploration of discourses integrated in genres using FDA.

\title{
2.2.2. Research goals
}

Interdiscursivity as defined in CGA not only reflects Foucault's (1972) theory of discourse, but also has similar goals. Foucault (1972) identifies two main research goals with his archaeological approach to discourse. The first is description, as evident in the following: "Archaeological analysis individualizes and describes discursive formations" (Foucault 1972: 157). This emphasis on description resonates well with Bhatia's view of interdiscursive analysis as serving an explanatory purpose rather than a normative or political agenda (see Section 2.3.3 below).

The second, less emphasized, aim of Foucauldian discourse analysis is critique. This is evident when Foucault (1972: 206) states that analyzing discourse should involve "diagnosis", a point that receives further elaboration in the following:

These pre-existing forms of continuity, all these syntheses that are accepted without question, these must remain in suspense. [...] [W] must show that they do not come about of themselves, but are always the result of a construction the rules of which must be known, and the justifications of which must be scrutinized: we must define in what conditions and in view of which analyses certain of them are legitimate; and we must indicate which of them can never be accepted in any circumstances. (Foucault 1972: 25-26) 
Here, Foucault argues that discourses are governed by "rules", and that some of these rules, once exposed, may reveal assumptions that should be condemned as unacceptable. In considering the acceptability or unacceptability of the rules of discourse, Foucault suggests a normative, even "political" (Shiner 1982: 383), role for discourse analysis. There is thus a clear disparity between the explanatory aims of CGA and the second aim of FDA which involves critique.

\subsection{Interdiscursivity in relation to developments in genre analysis}

As interdiscursivity is an under-investigated aspect of genre theory, it is useful to situate it in relation to three points of debate within genre studies more broadly: (1) text vs. context, (2) stability vs. change and (3) description vs. critique.

\subsubsection{Text vs. context}

Earlier genre studies were mainly concerned with internal (lexical and structural) textual aspects of genres (e.g. Bhatia 1993, Swales 1990). In more recent studies, however, greater emphasis has been placed on the interplay between text and context (Bhatia 2010). By examining how the discourses that circulate in society are evident in genres, CGA foregrounds the presence of context in genres (Bhatia 2010, Frow 2015).

\subsubsection{Stability vs. change}

The focus of early genre research lay primarily on identifying textual regularities (Bazerman 1988). More recent studies, however, have moved away from the notion that genres are static, prescriptive, even tyrannical (Coe 1994: 188) to acknowledging that genres are poised between the poles of "stability and change" (Berkenkotter/Huckin 1993: 6). Kain (2005: 377), for example, characterizes genres as "routine yet dynamic responses to communicative situations, driven by communal discursive practices and shaped by communities' accepted conventions". This tug between stability and change is captured metaphorically in the notion of "centripetal" and "centrifugal" forces operating in genres (Tardy 2011: 67).

The point of equilibrium between stability and change attained by specific textual instantiations of a genre is affected by a number of factors. Constraints are probably most profoundly felt in legally defined and regulated genres, or mandatory genres (Askehave/Zethsen 2003), such as the patient information leaflets that are required to accompany medicine produced by pharmaceutical companies in the EU (Fage-Butler 2011). At the same time, there is increasing recognition that the language used in genres reflects the outcome of choices (Swales 1990: 33), and that strategic interests may be reflected in genres (Bhatia 2014, Bhatia 2010). Thus a genre's position between the poles of stasis and change is affected by the interplay between genre constraints, on the one hand, and strategic objectives which are supported by interdiscursivity, on the other hand.

\subsubsection{Description vs. critique}

Most of the earlier genre studies were concerned with describing structural and lexical aspects to account for recurrent patterns in genres. However, the potential for a more critical agenda has been recognized for some time. Freedman/Medway (1994: 15), for example, identified in genre studies "a more reflexive and critical turn [...] in the making". Focusing on social and rhetorical aspects of genres, they say, "forces us all to reanalyse and rethink the social, cultural, political purposes of previously taken-for-granted genres, and leads to an archaeological unearthing of tacit assumptions, goals and purposes as well as the revealing of unseen players and the unmasking of others" (Freedman/Medway 1994: 2). In other words, examining the underlying assumptions of genres, which is possible using the analytical approaches of FDA, can expose and problematize ethical and political aspects. For Chouliaraki/Fairclough (1999), interdiscursive genre analysis supports the analysis of hegemonic ideologies, with clear implications for critical stance-tak- 
ing. Levina/Orlikowski (2009) take a similar line as they envisage genres as embedding power differentials.

Bhatia, the founding father of CGA, has tended to define its critical aims not in the Habermasian or Frankfurt school sense of critical (see, for example, Geuss 1981), but rather as a means of progressing beyond surface meanings towards identifying the strategic aims and professional cultures of the sender (Bhatia 2010: 35). Thus, interdiscursive analysis in CGA can expose an organization's "private intentions" (Bhatia 2010: 37).

According to Bhatia $(2014,2004,2012)$, interdiscursive analysis in CGA moves beyond description towards explanation, whilst eschewing the aim of promoting change. As Bhatia (2014: 9) clarifies: "CGA is not an initiative to change the professional practices of individual disciplinary, organizational and corporate communities, but to understand how professional writers use the language to achieve the objectives of their professions". Significantly, Bhatia (2014: 8-9) draws a line between the emancipatory aims of critical discourse analysis (CDA) (Fairclough/ Wodak 1997, van Dijk 2001) and the explanatory aims of CGA. However, the possibility remains within CGA for more evaluative or normative approaches, a point to which I return in Section 5.

\subsection{Analytical approaches used to analyse interdiscursivity}

As mentioned in the Introduction, numerous analytical approaches have been used to investigate interdiscursivity. For example, using linguistic analysis, Bhatia (2007) identifies four discourses in corporate annual reports: accounting, economics, public relations and legal. Although Bhatia (2014: 8-9) has distanced CGA from CDA, others have linked these methodologies. Koteyko (2009: 113-114), for example, subsumes CGA under CDA: "this paper uses the framework of 'critical discourse analysis' [...] which includes critical genre analysis", whilst Han (2014) combines the analytical approaches of CGA with CDA. Levina/Orlikowski (2009), on the other hand, perform critical genre analysis using sensitizing concepts from Bourdieu. FDA has yet to make explicit contributions to CGA, although its potential has been suggested (Fage-Butler 2013); this paper follows up on that suggestion.

\section{The methodology of Foucauldian discourse analysis}

The present section outlines the analytical approach within FDA (Foucault 1972) called statement function analysis, illustrating in Section 4 not only how it can be used to perform interdiscursive analysis, but also what it can be used to show.

If by 'methods', we mean systematic approaches applied to collecting and analyzing one's data (Grix 2002), then it is fair to say that Foucault (1972) in The Archaeology of Knowledge does not provide a discourse analytical method per se. However, Foucault (1972) has arguably defined both the discursive object of analysis and the aims of analysis in sufficient detail to make his archaeological approach operationalizable (Ahl 2007, Andersen 2003, Fage-Butler 2011, Graham 2011).

\subsection{Statements: the unit of analysis}

Although Fairclough (1992: 73) postulated three levels of analysis in CDA (text, discursive practice and social practice), only one level of analysis is relevant in FDA, namely, analysis of statements at the textual level. The social and discursive levels are subsumed under the textual level, as texts and talk consist of statements that reveal the discourses that determine the conditions of society. Foucauldian discourse analysis involves analyzing the statements in one's written or spoken data. Statements are like the "atom[s]" (Foucault 1972: 80) of discourse, where a discourse (or discursive formation) consists of statements that are interconnected and form a "regularity" (Foucault 1972: 38), such as statements that converge around the topics of probabilistic risk, biomedicine or corporate social responsibility. A discursive formation comprises all of the statements that relate to that discourse. 
Foucault (1972: 87) underlines that a statement, which is the unit of discourse, is not the same as a sentence, which is a syntactical unit. However, in order to be able to analyze statements, one needs to be able to say when a statement starts and ends. Andersen (2003: 11) clarifies how it is possible to determine borders around statements: as a statement is the smallest unit that has a constitutive effect, a new statement starts when a new discursive object is constructed.

\subsection{Statement function analysis}

As Foucauldian statements are functional entities (Foucault 1972: 87), it is the functions of statements that must be identified in discourse analysis. Graham (2005: 5) suggests employing the following question to identify the function of a statement: "What does it do and with what effects?", where what it "does" can be considered to relate to the constructive work that the statement performs, and "with what effects" relates to the effects in the particular discourse in which it has constructive effects. For example, 'God save the Queen' may be considered a statement. Its function is to construct the queen as worthy of blessing, and its constructive effect is royalist, as legitimacy is added to the queen as a country's figurehead through religious appeal.

Once the individual statements in one's data set are analyzed with regard to their constructive function, the resulting statement functions are then scrutinized for patterns in meaning, as identifying these makes it possible to spot which discourses are integrated into a genre.

\subsection{Data set}

The present study draws on Cornut et al. (2012) who, using move analysis (Swales 1990) on a data set of over eight million words, showed that the strategic plans of public and third-sector organizations (including hospitals), presented on the organizations' websites, involve 16 prototypical moves (Swales 1990). The data set analyzed in the present paper consists of strategic plans produced by three National Health Service (NHS) British hospitals, and published online:

- Ipswich Hospital (2009)

- Guy's and St. Thomas' (2014)

- Papworth Hospital (2014)

The present data set consists of just over 30,000 words. A larger data set was not chosen, as the focus of this paper is methodological as opposed to empirical. Of the 16 moves that Cornut et al. (2012) identified in strategic plans, the move called "priorities/goals" was the most prevalent; it was therefore selected for interdiscursive analysis in this paper. In Ipswich Hospital (2009), the move was evident in the section that was called "Five Year Vision" (pages 14-22); in Guy's and St. Thomas' (2014), it was evident in the section entitled "Our Strategy" (pages 11-20); and in Papworth Hospital (2014), priorities and goals were outlined in the sections that presented the hospitals' existing challenges and how they would be addressed (pages 10-33).

\section{Findings of the interdiscursive analysis}

Performing statement function on the move called "priorities/goals" means identifying the discourses that legitimate those priorities and goals. Using statement function analysis, three main discourses were evident in relation to the "priorities/goals" move: strategic management (e.g. Koskela 2013, Nag et al. 2007), public service accountability (Denhardt/Denhardt 2000, Rhodes 1994) and patient centeredness (e.g. Balint 1969, Mead/Bower 2000). Within strategic management, which was the most heavily integrated discourse, statement functions clustered around five distinct areas: commercial identity, responsiveness to context, economic sustainability, valuesbased leadership and core competences (see Sections 4.1.1 - 4.1.5 below). The discourse of public service accountability (presented in Section 4.2) was evident where the hospitals were constructed as striving to meet the public's health needs and expectations. The discourse of patient 
centeredness was evident in goals that constructed the patient as a unique individual, underlined the importance of the doctor-patient relationship and emphasized patient involvement (see Section 4.3). It should be noted that, for reasons of space, only one statement is included to illustrate each statement function. The statements are numbered (1) to (18) in the analysis. The results of the statement function analysis are presented in the text below in bold.

\subsection{The discourse of strategic management}

\subsubsection{Commercial identity}

In the following statement, the strategic plan of the hospital is constructed as an integral part of the overall business plan of the hospital:

(1) We are constantly refining our strategic plans as part of business planning and with all our partners. (Guys' and St. Thomas' 2014: 11)

Drawing on a similar conceptualization, statement function analysis reveals that hospitals aim to provide the best consumer care for patients:

(2) We want our patients to have a superb experience, in terms of outcome, safety and overall customer experience. (Ipswich Hospital 2009: 14)

These statements reflect the discourse of strategic management, one of whose hallmarks is the conceptualization of the organization as a commercial entity (Nag et al. 2007: 941).

\subsubsection{Responsiveness to context}

Strategies are also constructed as being informed by relevant standards which may come from external agencies or internal groups:

(3) Papworth's quality priorities are decided following consultation with clinical teams, Governors, Patient \& Public Involvement Committees and Healthwatch UK representatives. (Papworth Hospital 2014: 12)

The outward-looking nature of the hospitals is further emphasized in the construction of strategies as supportive of improved collaborations with relevant organizations and stakeholders:

(4) We will continue to implement changes to the way staff work to improve clinical services, including implementing new roles in key Trust developments. Staff will need to increasingly work in new and closer partnerships with other sectors such as social care, the voluntary sector and with mental health and primary care colleagues (Guy's and St. Thomas' 2014: 17)

The hospitals' strategies are discursively constructed as agile, informed by relevant standards, and answerable to external and internal agencies. These also link to the discourse of strategic management: responsiveness to an organization's context or environment has been identified as a central element of strategic management (de Geus 1997, Mintzberg et al. 2003, Nag et al. 2007); research indicates that organizations that are situationally aware and self-monitoring are more likely to be successful in delivering their strategies (Nohria et al. 2003).

\subsubsection{Operational management}

The strategic plans are concerned with the operational management of the hospitals. This is evident in statements that relate to defining the nature of the services that the hospitals should henceforth provide:

(5) We have identified that we need to invest in our capability to diagnostic [sic] patients more accurately, including investing in genetic diagnosis services. This will be particularly important in our priority clinical services - cancer, cardiovascular and children's services. (Guy's and St. Thomas' 2014: 12) 
Similarly, statement function analysis reveals that statements construct the deployment of physical resources as needing careful financial management:

(6) The Trust is also managing its capital programme carefully to ensure investments are prudent in the context of the relocation to the new hospital (e.g. the medical equipment replacement programme, refurbishment of theatres, labs and other facilities, and management of the estate). (Papworth Hospital 2014: 22)

Statements construct the effective management of human resources as linked, amongst other things, to greater quality and productivity:

(7) The key focus of our workforce strategy is ensuring our staff are supported to deliver safe, high quality and sustainable care seven days a week, improve staff satisfaction and engagement and ensure strong, empowered leadership. (Guy's and St. Thomas' 2014: 17)

Strategies regarding greater use of IT are motivated at least in part by the potentially cost-cutting affordances of new technologies:

(8) We expect to be able to reduce our staff numbers through increased use of automated processes and efficiencies. (Guy's and St. Thomas' 2014: 18)

The overarching strategies regarding operational management are constructed as having been validated by professional experts:

(9) Papworth has a successful track record of meeting growing demand for its services, and its activity projections for the period covered by the strategic plan have been developed with the involvement and support of commissioners and endorsed by independent expert reviews. (Papworth Hospital 2014: 22)

All in all, statement function analysis reveals that the strategies regarding the hospitals' operational management are constructed as prudent, well-informed, financially sustainable, and as defining the organization's future direction. These statement functions reflect the discourse of strategic management, as ongoing discussion of the organization's portfolio of offerings whilst meeting economic imperatives is a key aspect of corporate strategy (Mintzberg et al. 2003).

\subsubsection{Values-based leadership}

Statements construct the importance of leadership built on organizational values in facilitating the operationalization of the hospitals' strategies, for example:

(10) Leading the organisation through such major change will be challenging: critical in achieving support for this will be the focus on Papworth's values and in particular the benefits to patients and improvements in the quality of care. There is a need to engage and convince people, and overcome concerns about changes to established ways of working. (Papworth Hospital 2014: 14)

Here, committed leadership informed by values is invoked as a means of executing the changes outlined in the strategic plan. Again, this reflects the discourse of strategic management: strategic management is considered to rely on effective leadership predicated on team values and corporate values (Collier/Esteban 2007, Schaubroeck et al. 2007).

\subsubsection{Core competences}

Statement function analysis reveals that statements construct the hospitals' strategies as promoting knowledge by supporting quality and innovation within clinical research:

(11) The research vision, reflecting the Trust's position as an NHS provider, is to deliver timely, highquality, clinical research to drive forward improvements in patient care at Papworth, across the NHS and beyond. (Papworth 2014: 18)

Another priority area for strategic knowledge-related intervention relates to hospitals' ambitions to train highly qualified professional medical practitioners: 
(12) We aim to be a national leader in education reform through our research and teaching, by growing our graduate programmes and by collaborating with King's College London to develop innovative and forward thinking training. (Guy's and St Thomas' 2014: 17)

The strategies in the strategic plans also construct the hospitals' responsibility to share knowledge with the general public through public health educational initiatives, for example:

(13) We will build on our excellent reputation for cancer care and utilise our existing capacity by promoting public awareness to reduce the risk of developing cancer (in conjunction with NHS Suffolk) (Ipswich Hospital 2009: 21)

Statements 11-13 construct the hospitals' resolve to support the development and dissemination of new knowledge, with the hospitals' knowledge strategically identified as its core competence. Identifying core competences is a key aspect of strategic management (Prahalad/Hamel 1990).

\subsection{The discourse of public service accountability}

Statement function analysis reveals that statements construct the hospitals as being responsive to the health needs of the population they serve, for example:

(14) The hospital's development plans for the next five years address the main causes of death in our community and the needs of our catchment population. (Ipswich Hospital 2009: 16)

The public service nature of the hospitals, which are primarily publicly funded, is emphasized in statements that construct the hospitals as striving to meet public expectations:

(15) We want you to be proud of what we are doing as an NHS hospital and we want to make sure that what we are doing is what you want us to do. (Ipswich Hospital 2009: 22)

These statement functions underline the hospitals' long-term responsibilities towards healthcare service provision, with public accountability particularly relevant as public funds are used to cover hospitals' running costs. A sense of public ownership (Jo et al. 2012) is promoted in the second of the two statements.

\subsection{The discourse of patient centeredness}

Statements also construct hospitals as prioritizing care that is ethical, respectful of the patient as a unique individual:

(16) Our key principles are that care must be patient-focused, non-ageist and non-judgmental and will be delivered on the basis of need. (Ipswich Hospital 2009: 20)

Supporting interpersonal relations lie at the heart of hospitals' strategies, with focus on positive relations between medical practitioners and patients:

(17) The Trust's Quality Strategy will be revised during 2014/15 to [...] [i]ncorporate the Chief Nurse's 6 C's (care, compassion, courage, communication, competence, commitment). (Papworth 2014: 12)

Patients' involvement in decisions about their healthcare is similarly underlined as an important goal:

(18) In maternity services, we have an excellent record of home births and we will ensure that choice of place of birth continues. (Ipswich Hospital 2009: 19)

Patient centeredness, which is an approach to health communication (Balint 1969, Duggan et al. 2006) as well as a discourse (Dixon-Woods 2001, Fage-Butler 2013) that recognizes that both patients and doctors are individuals, that patients need to be respected and 'heard', and argues for greater involvement of patients in their healthcare, is clearly evident in Statements 16-18. 


\section{Discussion and Conclusion}

In this paper, FDA was used to analyze interdiscursivity in hospitals' strategic plans within a CGA perspective. Statement function analysis (Foucault 1972) of the move of "priorities/goals" identified the inclusion of the discourses of strategic management, public service accountability and patient centeredness. The heavy presence of the discourse of strategic management recalls a similar finding by Koskela (2013) where strategic management was identified as one of the main discourses in the strategy texts of Finnish insurance companies. The co-presence of the potentially jarring discourses of (corporate) strategic management and public service accountability is in keeping with the increasing trend towards corporatization of publicly funded hospitals (Preker/ Harding 2003). The patient centeredness discourse reflects the hospitals' concern to reflect an ethical paradigm within healthcare (Duggan et al. 2006) where the patient is conceived, not merely as a consumer or recipient of health services, but as an individual with unique needs. Such inclusion of discourses that relate to values and attributes with which organizations would like to identify themselves constitutes a central line of inquiry in CGA.

The analysis section of this paper illustrates the benefits of FDA for the investigation of interdiscursivity in CGA. Statement function analysis (Foucault 1972) makes it possible to conduct a fine-grained analysis that supports the identification of the discourses that are integrated in genres. It involves an inductive, bottom-up approach, as actual statements are the object of analysis. Statement function analysis makes it possible to identify the specific elements of the discourses that the writer of the text considered relevant to integrate. In this way, FDA makes it possible to identify the discursive elements that are used "to achieve often complex and intricate corporate objectives" (Bhatia 2012: 20). However, the process of interpreting the statement functions to identify the discourses to which they relate is clearly assisted by the analyst's familiarity with relevant theoretical literature. As such, approaching the data both inductively and deductively is advised. Acquaintance with theoretical literature also helps analysts present their findings in a way that is meaningful for the relevant academic community (here, for example, organizational studies).

This paper illustrates the descriptive strengths of FDA for CGA, where discourses and their component elements may be mapped out using statement function analysis. However, as noted in Section 2, FDA facilitates both critical and descriptive objectives. An area that would benefit from further discussion is the question of the 'critical' in CGA, particularly if FDA is used to analyze interdiscursivity (for further discussion of this point, see Bhatia's article in this thematic section). As a starting point, one could critically consider the juxtaposition of very different discourses, such as strategic management and patient centeredness, or strategic management and public service accountability in the same genre. A critical approach is in any case pertinent in relation to discourse: the discourse of strategic management, for example, has received considerable critical attention (Greckhamer 2010, Phillips et al. 2008), and even patient centeredness is not without its critics (de Haes 2006, Olesen 2004).

The limitations of this paper point in the direction of future studies. First, this paper works with a relatively small data set and with only one generic move. An empirical study of strategic plans that employed a larger data set and examined a greater number of moves using FDA would therefore be a valuable follow-up; other discourses are likely to be evident in a larger data set. Second, the analytical potential of FDA to contribute to interdiscursive analysis within CGA is not exhausted in this paper: it would also be very valuable to show using FDA how interdiscursivity constructs identities for the sender in organizational genres.

\section{Conclusion}

I hope that this paper will provide impetus to further discussions about how to conduct CGA research in ways that contribute to organizational research, particularly given the discursive turn within organizational research (Alvesson/Kärreman 2000). Interdiscursive analysis of genres de- 
livers particular benefits to the study of organizations, as discourses provide the basis for legitimation (van Leeuwen 2007), indicate the cultural norms within which organizations operate (Bhatia 2010), and construct organizational identity (Alvesson/Kärreman 2011, Leclercq-Vandelannoitte 2011). Analyzing the discursive unfolding of organizational strategy will deliver insights into the meanings that are chosen, as well as provide critical purchase on them. As such, CGA has much to offer the "strategy as practice" school within organizational studies (Barry/Hansen 2008, Cornut et al. 2012, Johnson et al. 2007).

CGA is a relatively new methodology, and so far it has primarily been used within organizational research to investigate professional genres. However, the critical study of genre has even broader potential. As Frow (2015: 166) aptly points out: "what we learn, in 'doing' genre [...] is the values we share or don't share with others and the means with which to challenge or defend them. Through the use of genres we learn who we are, and encounter the limits of our world". As such, an investigation of interdiscursivity in genres can support the critical agenda within qualitative research more generally (Denzin/Lincoln 2011), and FDA can make significant contributions to this important endeavor.

\section{References}

Ahl, Helene 2007: A Foucauldian Framework for Discourse Analysis. In Helle Neergaard/John P. Ulhøi (eds.), Handbook of Qualitative Research Methods in Entrepreneurship. Cheltenham: Edward Elgar, 216-250.

Allen, Graham 2000: Intertextuality. London: Routledge.

Alvesson, Mats/Kärreman, Dan 2011: Decolonizing Discourse: Critical Reflections on Organizational Discourse Analysis. In Human Relations 64:9, 1121-1146.

Alvesson, Mats/Kärreman, Dan 2000: Varieties of Discourse: On the Study of Organizations through Discourse Analysis. In Human Relations 53:9, 1125-1149.

Andersen, Niels Å. 2003: Discursive Analytical Strategies: Understanding Foucault, Koselleck, Laclau, Luhmann. Bristol: The Policy Press.

Askehave, Inger/Zethsen, Karen K. 2003: Communication Barriers in Public Discourse. In Document Design 4:1, 2241.

Bakhtin, Mikhail 1986: Speech Genres and Other Late Essays. Austin: University of Texas Press.

Balint, Enid 1969: The Possibilities of Patient-Centered Medicine. In Journal of the Royal College of General Practitioners 17:82, 269-276.

Barry, Daved/Hansen, Hans (eds.) 2008: The Sage Handbook of New Approaches in Management and Organization. London: Sage.

Bazerman, Charles 1988: Shaping Written Knowledge: The Genre and Activity of the Experimental Article in Science. Madison: University of Wisconsin Press.

Berkenkotter, Carol/Huckin, Thomas N. 1993: Rethinking Genre from a Sociocognitive Perspective. In Written Communication 10:4, 475-509.

Bhatia, Vijay 2014: Analysing Discourse Variation in Professional Contexts. In Vijay Bhatia/Stephen Bremner (eds.), The Routledge Handbook of Language and Professional Communication. London: Routledge, 3-12.

Bhatia, Vijay K. 2012: Critical Reflections on Genre Analysis. In Ibérica 24, 17-28.

Bhatia, Vijay K. 2010: Interdiscursivity in Professional Communication. In Discourse \& Communication 4:1, 32-50.

Bhatia, Vijay K. 2004: Worlds of Written Discourse. London: Continuum.

Bhatia, Vijay K. 1993: Analysing Genre: Language use in Professional Settings. London: Longman.

Candlin, Christopher N. 2006: Accounting for Interdiscursivity: Challenges to Professional Expertise. In Maurizio Gotti/Davide S. Giannoni (eds.), New Trends in Specialized Discourse Analysis. Bern: Peter Lang, 21-45.

Candlin, Christopher N./Maley, Yon 1997: Intertextuality and Interdiscursivity in the Discourse of Alternative Dispute Resolution. In Britt-Louise Gunnarsson/Per Linell/Berndt Nordberg (eds.), The Construction of Professional Discourse. London: Longman, 201-222.

Chouliaraki, Lilie/ Fairclough, Norman 1999: Discourse in Late Modernity. Edinburgh: Edinburgh University Press.

Coe, Richard M. 1994: An Arousing and Fulfilment of Desires: The Rhetoric of Genre in the Process Era - and Beyond. In Aviva Freedman/Peter Medway (eds.), Genre and the New Rhetoric. London: Taylor \& Francis, 181-190. 
Collier, Jane/Esteban, Rafael 2007: Corporate Social Responsibility and Employee Commitment. In Business Ethics: A European Review 16:1, 19-33.

Cornut, Francis/Giroux, Hélène/Langley, Ann 2012: The Strategic Plan as a Genre. In Discourse \& Communication 6:1, 21-54.

de Geus, Arie P. 1997: The Living Company. Boston: Harvard Business School Press.

de Haes, Hanneke 2006: Dilemmas in Patient Centeredness and Shared Decision Making: A Case for Vulnerability. In Patient Education and Counseling 62:3, 291-298.

Denhardt, Robert B./Denhardt, Janet V. 2000: The New Public Service: Serving rather than Steering. In Public Administration Review 60:6, 549-559.

Denzin, Norman K./Lincoln, Yvonna S. 2011: Preface. In Norman K. Denzin/Yvonna S. Lincoln (eds.), The Sage Handbook of Qualitative Research. 4th edn. Thousand Oaks, CA: Sage, ix-xvi.

Dixon-Woods, Mary 2001: Writing Wrongs? An Analysis of Published Discourses about the Use of Patient Information Leaflets. In Social Science \& Medicine 52:9, 1417-1432.

Duggan, Patrick S./Geller, Gail/Cooper, Lisa A./Beach, Mary C. 2006: The Moral Nature of Patient-Centeredness: Is it "Just the Right Thing to Do"? In Patient Education and Counseling 62:2, 271-276.

Fage-Butler, Antoinette M. 2013: Improving Patient Information Leaflets: Developing and Applying an Evaluative Model of Patient Centeredness for Text. In Communication \& Medicine 10:2, 105-115.

Fage-Butler, Antoinette M. 2011: Towards a New Kind of Patient Information Leaflet? Risk, trust and the value of patient centeredness (Ph.D.). Aarhus: Aarhus University.

Fairclough, Norman 1992: Intertextuality in Critical Discourse Analysis. In Language and Education 4:3, 269-293.

Fairclough, Norman/Wodak, Ruth 1997: Critical Discourse Analysis. In Teun A. van Dijk (ed.), Discourse as Social Interaction. Discourse Studies: A Multidisciplinary Introduction. Vol. 2. London: Sage, 258-284.

Foucault, Michel 1972: The Archaeology of Knowledge. New York: Pantheon.

Freedman, Aviva/Medway, Peter 1994: Locating Genre Studies. In Aviva Freedman/Peter Medway (eds.), Genre and the New Rhetoric. London: Taylor \& Francis, 1-22.

Frow, John 2015: Genre. 2nd edn. London: Routledge.

Genette, Gérard 1997: Palimpsests: Literature in the Second Degree. Lincoln: University of Nebraska Press.

Geuss, Raymond 1981: The Idea of a Critical Theory: Habermas and the Frankfurt School. Cambridge: Cambridge University Press.

Glynos, Jason/Howarth, David 2007: Logics of Critical Explanation in Social and Political Theory. Abingdon: Routledge.

Graham, Linda J. 2011: The Product of Text and 'Other' Statements: Discourse Analysis and the Critical use of Foucault. In Educational Philosophy and Theory 43:6, 663-674.

Graham, Linda J. 2005: Schooling and 'Disorderly' Objects: Doing Discourse Analysis using Foucault [online]. http:// eprints.qut.edu.au/2806/1/2806.pdf (accessed 9 January 2015).

Greckhamer, Thomas 2010: The Stretch of Strategic Management Discourse: A Critical Analysis. In Organization Studies 31:7, 841-871.

Grix, Jonathan 2002: Introducing Students to the Generic Terminology of Social Research. In Politics 22:3, 175-186.

Guy's and St Thomas' NHS Foundation Trust 2014: Summary of Strategic Plan 2014-2019 [online]. https://www.guysandstthomas.nhs.uk/resources/publications/strategy/aa-strategic-plan2014-19.pdf (accessed 11 November 2014).

Han, Zhengrui 2014: The Marketization of Public Discourse: The Chinese Universities. In Discourse \& Communication 8:1, 85-103.

Hook, Derek 2001: Discourse, Knowledge, Materiality, History: Foucault and Discourse Analysis. In Theory \& Psychology 11:4, 521-547.

Ipswich Hospital 2009: Our Passion, Your Care. Five-Year Strategic Plan 2009-2014 [online]. http://www.ipswichhospital.nhs.uk/aboutourhospital/Documents/Publication\%20Scheme/Five\%20Year\%20Strategic\%20Plan.pdf (accessed 11 November 2014).

Jo, Tae-Hee/Chester, Lynne/King, Mary C./Cumbers, Andrew/McMaster, Robert 2012: Rethinking Public Ownership and Participation. In On the Horizon 20:3, 172-181.

Johnson, Gerry/Langley, Ann/Melin, Leif/Whittington, Richard 2007: Strategy as Practice: Research Directions and Resources. Cambridge University Press.

Jones, Rodney H. 2012: Discourse Analysis: A Resource Book for Students. London: Routledge. 
Kain, Donna J. 2005: Constructing Genre: A Threefold Typology. In Technical Communication Quarterly 14:4, 375409.

Koskela, Merja 2013: Same, Same, but Different: Intertextual and Interdiscursive Features of Communication Strategy Texts 389-407. In Discourse \& Communication 7:4, 389-407.

Koteyko, Nelya 2009: 'I Am a very Happy, Lucky Lady, and I Am Full of Vitality!' Analysis of Promotional Strategies on the Websites of Probiotic Yoghurt Producers. In Critical Discourse Studies 6:2, 111-125.

Kristeva, Julia 1980: Word, Dialogue and Novel. In Julia Kristeva (ed.), Desire in Language. Oxford: Blackwell, 64-91.

Leclercq-Vandelannoitte, Aurélie 2011: Organizations as Discursive Constructions: A Foucauldian Approach. In Organization Studies 32:9, 1247-1271.

Levina, Natalia/Orlikowski, Wanda J. 2009: Understanding Shifting Power Relations within and Across Organizations: A Critical Genre Analysis. In Academy of Management Journal 52:4, 672-703.

Mead, Nicola/Bower, Peter 2000: Patient-Centeredness: A Conceptual Framework and Review of the Empirical Literature. In Social Science \& Medicine 51:7, 1087-1110.

Mey, Jacob L. 2001: Pragmatics: An Introduction. 2nd edn. Oxford: Blackwell.

Mintzberg, Henry/Lampel, Joseph B./Quinn, James B./Ghoshal, Sumantra 2003: The Strategy Process: Concepts, Contexts, Cases. 2nd edn. Harlow: Pearson Education.

Nag, Rajiv/Hambrick, Donald C./Chen, Ming-Jer 2007: What is Strategic Management, really? Inductive Derivation of a Consensus Definition of the Field. In Strategic Management Journal 28:9, 935-955.

Nohria, Nitin/Joyce, William/Roberson, Bruce 2003: What really Works. In Harvard Business Review 81:7, 42-52.

Olesen, Frede 2004: Striking the Balance: From Patient-Centred to Dialogue-Centred Medicine. In Scandinavian Journal of Primary Health Care 22:4, 193-194.

Papworth Hospital 2014: Strategic Plan 2014-2019 [online]. http://www.papworthhospital.nhs.uk/docs/about/Papworth-Hospital-Strategic-Plan-2014-19.pdf (accessed 10 December 2014).

Phillips, Nelson/Sewell, Graham/Jaynes, Steve 2008: Applying Critical Discourse Analysis in Strategic Management Research. In Organizational Research Methods 11:4, 770-789.

Prahalad, C.K./Hamel, Gary 1990: The Core Competence of the Corporation. In Harvard Business Review 68:3, 79-91.

Preker, Alexander S./Harding, April (eds.) 2003: Innovations in Health Service Delivery: The Corporatization of Public Hospitals. Washington, DC: World Bank Publications.

Rhodes, Rod A. 1994: The Hollowing Out of the State: The Changing Nature of the Public Service in Britain. In The Political Quarterly 65:2, 138-151.

Schaubroeck, John/Lam, Simon S./Cha, Sandra E. 2007: Embracing Transformational Leadership: Team Values and the Impact of Leader Behavior on Team Performance. In Journal of Applied Psychology 92:4, 1020.

Shiner, Larry 1982: Reading Foucault: Anti-Method and the Genealogy of Power-Knowledge. In History and Theory 21:3, 382-398.

Simons, Jon 1995: Foucault \& the Political. London: Routledge.

Soyland, A. J./Kendall, Gavin 1997: Abusing Foucault: Methodology, Critique and Subversion. In History and Philosophy of Psychology Newsletter 25, 9-17.

Swales, John M. 1990: Genre Analysis: English in Academic and Research Settings. Cambridge: Cambridge University Press.

Tardy, Christine M. 2011: Genre Analysis. In Ken Hyland/Brian Paltridge (eds.), The Continuum Companion to Discourse Analysis. London: Continuum, 54-68.

van Dijk, Teun A. 2001: Critical Discourse Analysis. In Schiffrin, Deborah/Tannen, Deborah/Hamilton, Heidi E. (eds.), The Handbook of Discourse Analysis. Malden, Mass.: Blackwell, 352-371.

van Leeuwen, Theo 2007: Legitimation in Discourse and Communication. In Discourse \& Communication 1:1, 91-112. 